\title{
FOUNDATION OF REPLACING THE PARAMETERS OF TREATMENT SET SOFTENING IN A GARDEN RAW SPACE IN AN EARLY SPRING
}

\author{
S.Xudoyberdiev - D.T.S., Professor, B.R.Boltaboev - C.T.S., Associate professor, \\ A.M.Abdumannopov - Researcher \\ Andijan branch of the Tashkent State Agrarian University \\ http://doi.org/10.35410/IJAEB.2019.4462
}

\begin{abstract}
In order to prepare, the garden raw space fields, for planting, the soil treatment set softening is replaced in two lines.

In this article is represented the scientific results of replacing softenings according to each other. It is clarified that, because of the treatment depth is for $15 \mathrm{~cm}$, the replacing differs for $36 \mathrm{~cm}$ in an across distance, no less than $32 \mathrm{~cm}$ in an along distance.
\end{abstract}

Keywords: Garden raw space, combined set, softening, treatment depth, bow hand, across and along distance

\section{INTRODUCTION}

Farmers in the newly formed gardens 4 ... For 5 years, the nurseries have been able to bring in a variety of orchards and vegetables. For these people, a number of hurricane fields are searched for, and the early spring springs are harvested. There is currently no aggregate of aggregate aggregation in the United States. This is why each process comes with a separate unit. As a result, frequent penetration of aggregates has a negative impact on the intensity of tufting and contributes to savings.

After counting the storms, a number of bushes came into the area and the unit was designed to produce a spring processor [1]. The two chess-boards are equipped with two-legged zigzag brushes, small crusher grinders, tampons, arcane mountings, and backhands. In the early spring in the autumn the work was done to the unit, as it was necessary for the site to be searched.

The main thing in the development of the crop is the fact that the field is looking for a fall. In order to make the most effective works, the distribution of the right five-dimensional zirconia, ie the distance caused by ularings, and the split between the two rows, becomes the most straightforward distance around the rows.

The rule is a part of the work-out aggregation of the pelvic five-dimensional body. 


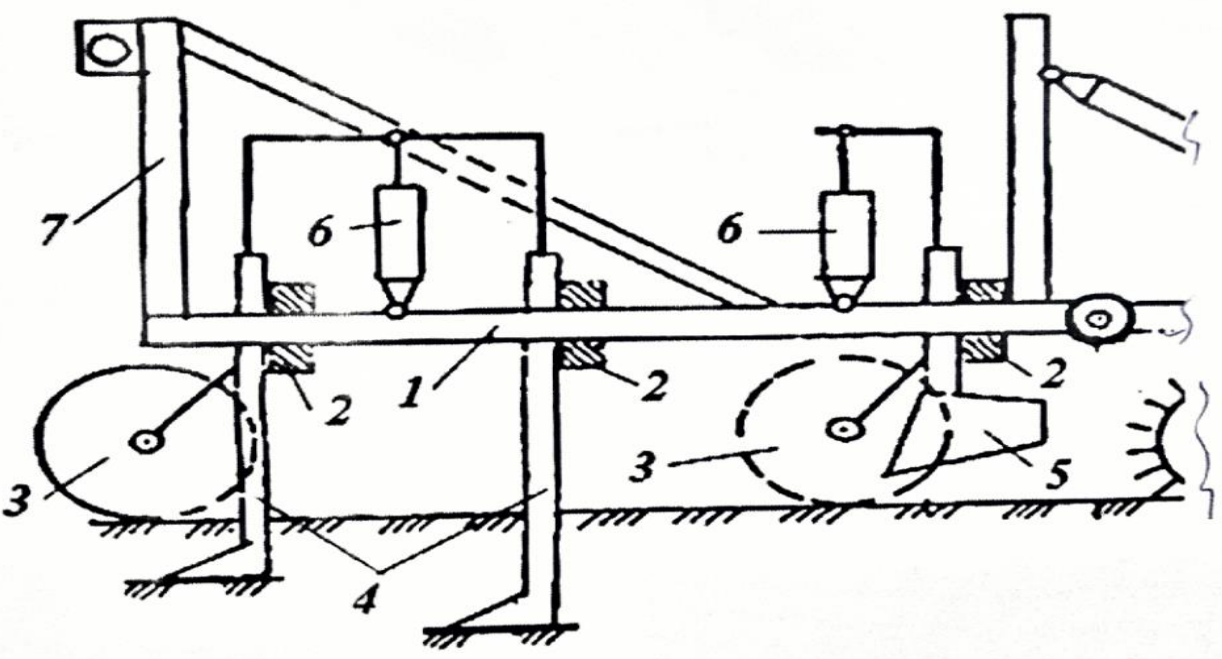

1, 2 - Hinged and cross-flange, 3-wheel drive, 4-hinged five-sided zigzag, 5-back cutter, 6hydro cylinder, 7-axle construction.

Picture 1 The part of the area where the lawn mowers have been demolished to allow the area to be parked.

The purpose of the study is to base the adjacent horizontal five-sided zigzag angles on each other with relative and long distance.

For these distances, we use the schema of a two-dimensional double-stroke scheme

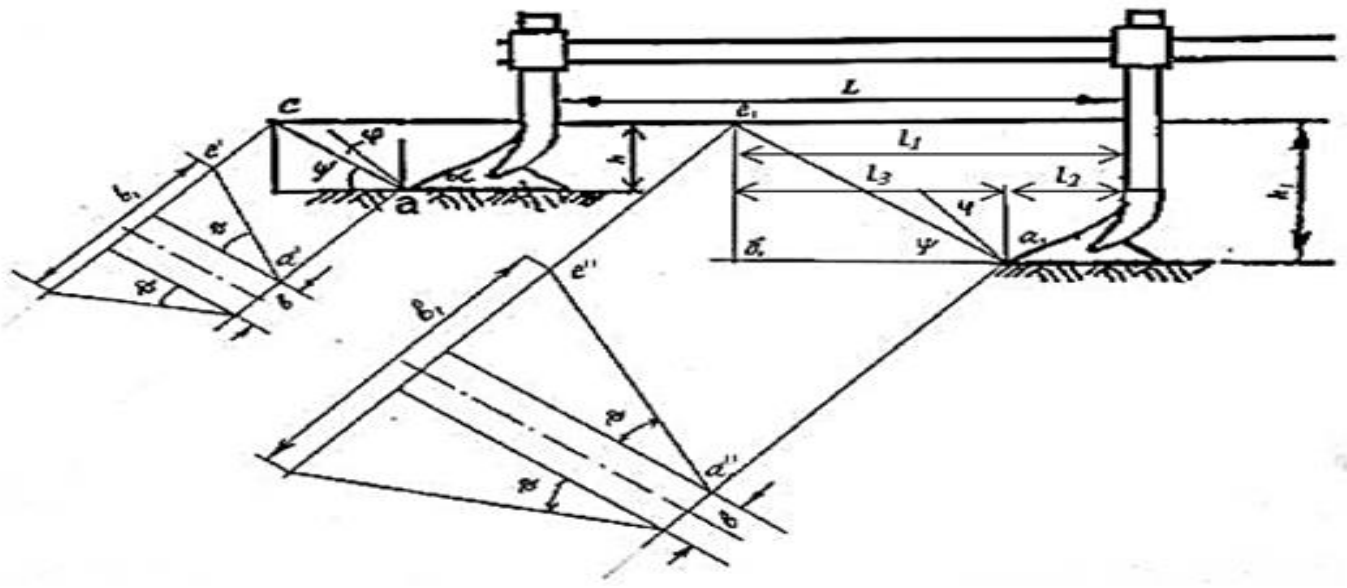

Figure 2. Schematic diagram of cross-sectional distance caused by two-dimensional pyramid. 
Thus, the right-hand slinging jaws (as we call the annoyance) move deeper into the $\mathrm{h}$, while the second row moves horizontally or at a depth of h1. The deformed vertex is bounded by the axis of the friction $\varphi$ angled from the normal inclination () by the inclination of the axis at the angle of inclination.

At the same time, the deformity of the tufting defect is determined by:for clumsy

Killing Catheter

Here are: b1, b3 - cross-sectional valves for precision-driven deformation for bending and kettling;

$\mathrm{b}, \mathrm{b} 2$ is a right-angled pliers. In case of business $\mathrm{b}=\mathrm{b} 2$;

$\Theta$ - Snake Corner.

Cunningham:

$h$ : h1 - depth of rotation of the organs and joints of the organs, cm;

$\varphi$ - corneal friction angle of the cornea, degree;

$\alpha$ - the entrance of the working organ to the hill, degree

Not far

Let us clarify the value of the value of the snake angle [2], ie

At this point: $\varphi 2$ - the angle of internal friction of tufting, for calculations $\varphi 2=30 \ldots 450$.

It will be long gone.

In practice, the depth of the movement of the organs of the body is inevitable. However, the depth of corrosion coefficients of the working organism is not constant.

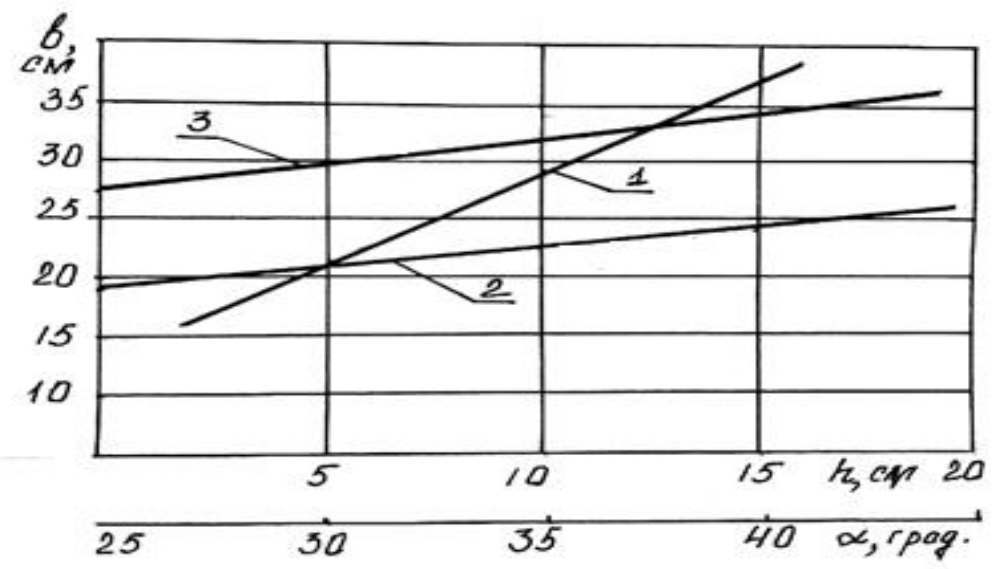


1. $b=f(h) ; 2 \cdot b=f(\alpha), h=5 \mathrm{~cm} \cdot 3 \cdot b=f(\alpha) ; h=10 \mathrm{~cm}$

Picture 3 Changes in the depth of the b л тек тек да да да $\mathrm{h} \mathrm{h} \mathrm{h} \mathrm{h} \mathrm{h} \mathrm{h} \mathrm{h} \mathrm{h}$

If the fringing of the fingertips shows the velocity distribution in the vertical axis, the graph of the zirshishshine will be in line with the picture. In this case, the working body depth of $h=10$ $\mathrm{cm}, \mathrm{h} 1=15 \mathrm{~cm}$, and the corneal angle $\alpha$ and the corners Mop are considered the same for all calculations. , the distance traveled by the cross-beams may be determined.

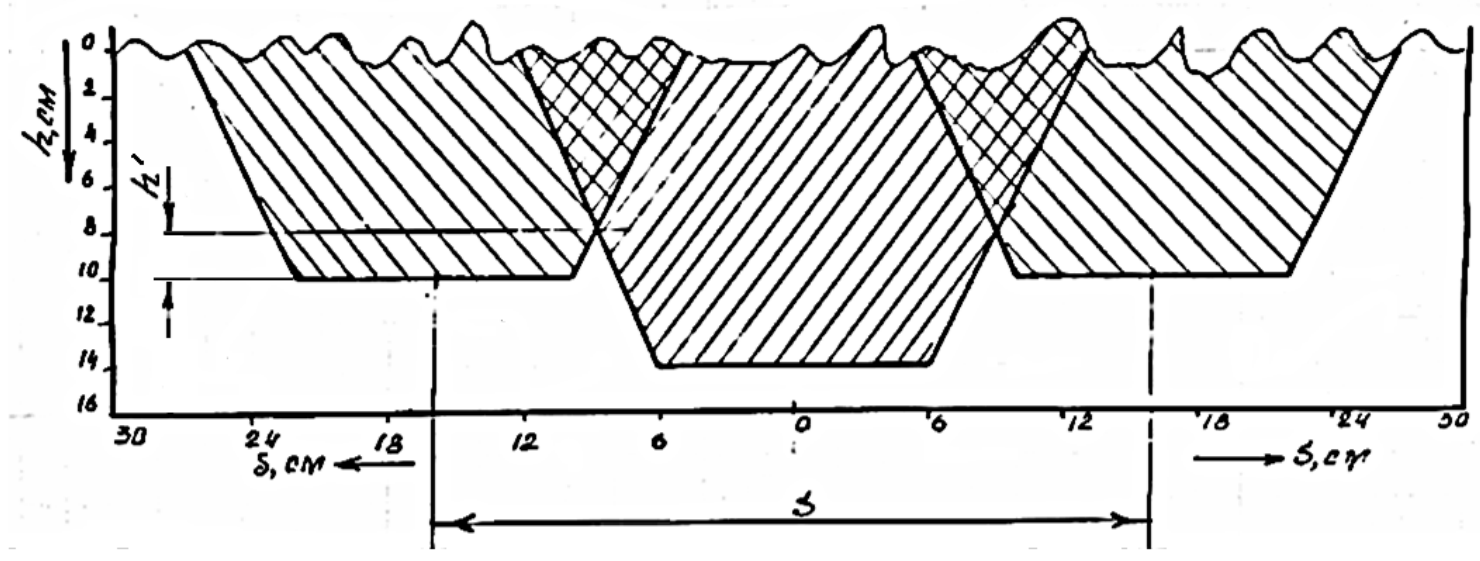

Figure 4 - The diagonal diagonal of the trimmed hinged fingers (cross-sectional)

For bunching, the diagram should be on a set scale. An insulated Yuzu with a faded collar with a $\mathrm{h} 1=0.5 \mathrm{~h}$ height, the first line of the hinge, with a right-wing fingertip, found a distance of $\mathrm{S}=$ $36 \mathrm{~cm}$, but this condition did not always occur.

The minimum circular distance caused by glaciers is determined by $11=12+13$. Due to the fact that the working organism is responsible for harvesting, the true L-distance larynx must be distributed over the distance 11, that is, the conditions must be met.

$\mathrm{L}>11$

from a triangle

Here: $\psi$ - sinusellar sinus sinus sinus angle, degree;

12 - The length of the fingertips relative to the handle, $\mathrm{cm}$.

It is possible to express precisely the expression of the sinus angle, which is the maximal level of the right hemisphere [3]:

This is: $\varphi 1, \varphi 2$ - corrugated corrugated corners and internal friction angles, degree.

At the same time, the length defines: 
Constructive parameters (for example, 12) are clearly defined in the working bodies, with the depth of 11 -fold and the right angles to the right angles to the right hemisphere. The $11=1,300$, $\varphi 2=400$ catalytic rectangular displacements are shown in Fig. 5

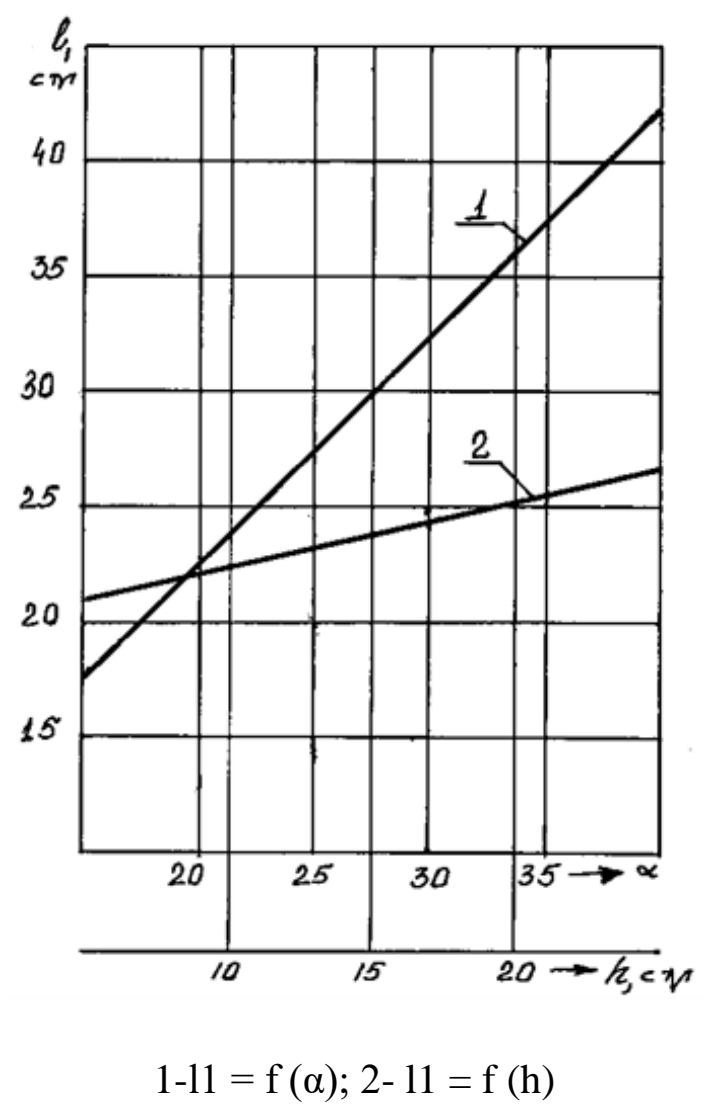

Figure 5. The minimum distance between the working bodies and the right angles to the depth of the penis and the depth of handling.

Therefore, when the true outer body is used, the Uarning-shaped cross-sectional area has a significant effect on the depth of the corrugation. When $\mathrm{h}=10 \mathrm{~cm}$, it is $23 \mathrm{~cm}$.

If the condition> 11 is the calculation, the true distance must be greater than the specified distance $(11=32 \mathrm{~cm})$. If the actual distance from the installation of the working bodies is not an option, then the distance should be smaller than the calculated distance.

The conclusion is that, when using a jasmine panther, the bore depth should not be more than 15 $\mathrm{cm}$.

\section{REFERENCES}


International Journal of Agriculture, Environment and Bioresearch

Vol. 4, No. 06; 2019

ISSN: 2456-8643

1. Khudoyberdiev TS, Khudoyorov AN, Boltaboev BR, Abdumannopov A. A new technology of gardening nurseries. Irrigation and Melioration 2019 - No. 1, 46 ... 50 p.

2.Gnilomedov VV Propagation of the propagated culverts in the // // Izvestiya Kuibyshevskiy breeding institute. 15.5 Kuibyshevskoye retreat. 1969 - 20.. 32 page.

3. Goryachkin VP Sbornik Sochi in 3-x Volume Search 2d, L.D. 1 - Moscow.Kolos, 1968 - 730 pages. 